\title{
Neurofibroma de Tireóide em Uma Paciente com Neurofibromatose Tipo 1
}

\begin{abstract}
RESUMO
A neurofibromatose tipo 1 (NF1), também conhecida como doença de von Recklinghausen, é uma doença autossômica dominante com alto grau de variabilidade da expressão clínica, comumente envolvida na formação de tumorações na maioria das vezes de origem benigna, localizadas principalmente na região da cabeça e do pescoço, sendo a tireóide acometida raramente. Porém existe na literatura a associação com carcinoma medular da tireóide (CMT), necessitando sempre sua exclusão. Relatamos o caso de uma paciente com NF1, com um nódulo de tireóide não-funcionante e sintomas obstrutivos. Foi realizada ressecção cirúrgica da lesão, com achados histopatológicos compatíveis com neurofibroma em tecido tireoidiano. A importância desse caso deve-se não só à raridade dessa apresentação da NF1, mas também à possibilidade de associação desta com CMT, tumor agressivo com possibilidade de cura pela ressecção cirúrgica. (Arq Bras Endocrinol Metab 2008;52/1:131-133)
\end{abstract}

Descritores: Doença de von Recklinghausen; Neurofibromatose tipo 1; Nódulo de tireóide; Carcinoma medular de tireóide

\section{ABSTRACT}

Neurofibroma of Thyroid in a Patient with Neurofibromatosis Type 1. The neurofibromatosis type 1 (NF1), also known as von Recklinghausen's disease, is an autosomal dominant disorder, with high degree of variability of clinical expression, usually involved with formation of tumors, with benign origin in the majority of cases mainly localized in the region of the head and neck and rarely incident in the thyroid area. However, the association with medullary carcinoma of the thyroid (MCT) exists in literature and needs to be excluded. We report a case of a patient with NF1, nonfunctional thyroid nodule and obstructive symptoms. Surgical resection of lesion was performed, with histopathologic findings compatible with neurofibroma in thyroid tissue. This case is relevant not only because of the rarity of the presentation of NF1, but also due to the likely association with MCT, an aggressive tumor that can be cured by surgery. (Arq Bras Endocrinol Metab 2008;52/1:131-133)

Keywords: Von Recklinghausen's disease; Neurofibromatosis type 1; Thyroid nodule; Medullary carcinoma of thyroid

\section{INTRODUÇÃO}

$\mathrm{O}$ S NÓDULOS DA TIREÓIDE APRESENTAM alta incidência na população geral, sendo o maior desafio diagnóstico a exclusão de lesão tumoral maligna. $\mathrm{Na}$ neurofibromatose tipo l (NFl) ou doença de von Recklinghausen, o comprometimento da tireóide é incomum, havendo poucos relatos de neuro- apresentação de caso

\author{
Mateus Dornelles SeVero \\ VerônICA DENARDIN da Rosa \\ Diego Michelon De CarlI \\ Maristela de Oliveira Beck \\ MELISSA FALSTER DANBERMAM
}

Serviço de Clínica Médica do Hospital Universitário de Santa Maria da Universidade Federal de Santa Maria, RS, Brasil (MDS, VDR, DMC, MFD); Serviço de Patologia do Hospital Universidade Santa Maria, RS, Brasil (MFD).

Recebido em 29/08/2007 Aceito em 10/10/2007 
fibroma adjacente à tireóide e raríssimos relatos de neurofibroma na glândula tireóide $(1,2)$. Entretanto existe na literatura uma associação entre NFl e carcinoma medular de tireóide (CMT) (3), que em virtude de sua agressividade deve ser sempre excluído nesses pacientes.

\section{RELATO DO CASO}

Sexo feminino, 31 anos, natural e procedente de Santiago, Chile, internada com queixas de nódulo cervical anterior, notado inicialmente há três anos, com evolução progressiva, acompanhado de odinofagia, sensação de opressão cervical, perda auditiva à direita e disfonia. Um ano antes da internação, realizou ecografia de tireóide que evidenciou glândula de dimensões aumentadas à custa de lobo direito, com parênquima glandular de textura heterogênea e imagem nodular hipoecogênica, medindo 41 x $15 \mathrm{~mm}$ em lobo direito. Exames da função tireoidiana foram normais. Ao exame clínico, apresentava bom estado geral; voz soprosa; importante assimetria de face; manchas café-com-leite, a maior localizada no dorso, medindo 30 cm em seu maior diâmetro; presença de nódulos cutâneos em dorso, membros inferiores e superiores; além de efélides em regiões axilares e inguinais.

A oroscopia demonstrava hemihipertrofia da língua à direita, com função motora preservada. A tireóide estava aumentada de tamanho à custa de nódulo medindo aproximadamente $5 \mathrm{~cm}$ de diâmetro em lobo direito, doloroso, de consistência elástica, contornos bem definidos e móvel à deglutição; o restante da glândula tinha semiologia normal. Não foram palpadas linfonodomegalias. Apresentava surdez neurossensorial à direita. Os demais achados do exame físico foram normais.

Paciente referia ter notado o aparecimento dos nódulos subcutâneos na adolescência e seus dois filhos tinham manchas de morfologia semelhante as suas em membros e dorso. Não fumava, não ingeria bebidas alcoólicas e negava comorbidades. Seus pais eram hígidos e sem alterações semelhantes.

Foi realizada punção aspirativa com agulha fina (PAAF) do nódulo da tireóide que demonstrou presença de poucas células foliculares e material colóide ou degenerativo, sendo o resultado inconclusivo para excluir neoplasia maligna. Novos exames laboratoriais, para avaliar função tireoidiana e de marcadores tumorais, mostraram TSH, T4 livre, calcitonina e antígeno cárcino-embrionário (ACE) dentro dos limites da normalidade. Exame oftal- mológico de fundo de olho e lâmpada de fenda, solicitados para pesquisar comprometimento ocular da NFl (gliomas e hamartomas de íris), foram normais. Na telelaringoscopia, realizada para avaliar a disfonia da paciente, havia paresia de prega vocal esquerda. A ressonância nuclear magnética de partes moles do pescoço, solicitada para avaliar comprometimento do nervo laríngeo recorrente esquerdo, não evidenciou outras lesões além do nódulo de tireóide e na tomografia de orelha direita não havia comprometimento de oitavo par.

A biópsia dos nódulos cutâneos mostrou neurofibromas múltiplos. A paciente foi encaminhada à cirurgia de ressecção parcial de tireóide e biópsia de língua que demonstraram, respectivamente, neurofibroma de tireóide e bócio colóide (Figuras 1 e 2) e neurofibroma de língua.

Atualmente a paciente encontra-se em acompanhamento ambulatorial com boa evolução clínica.

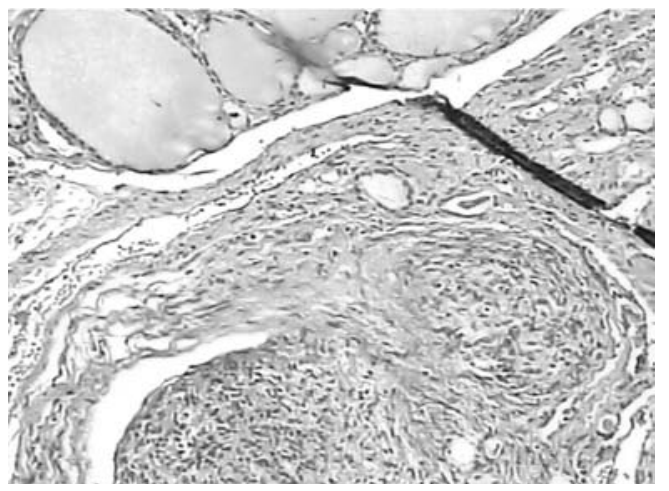

Figura 1. Transição entre a neoplasia (parte inferior da imagem) e o tecido tireoidiano (parte superior esquerda) 10x (H\&E).

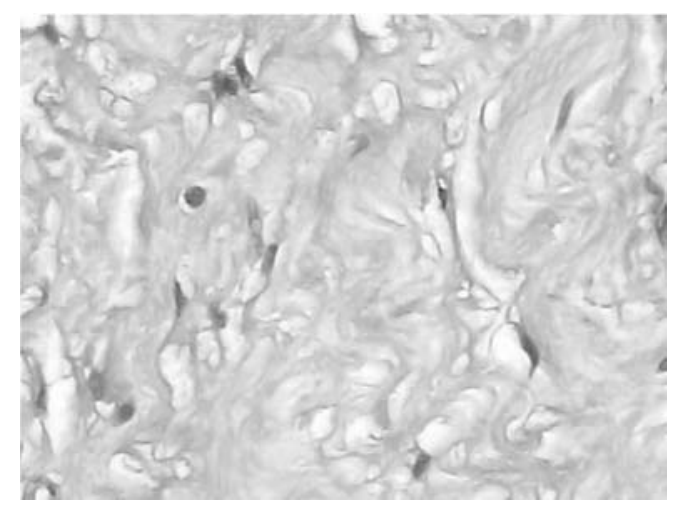

Figura 2. Imagem em maior aumento (40 x) mostrando o detalhe citológico das células neoplásicas fusiformes, brandas, com citoplasma e núcleo ondulados, sem atividade mitótica aparente (H\&E). 


\section{DISCUSSÃO}

A incidência da NFl é de um para três mil nascidos vivos. Os neurofibromas são tumores benignos, geralmente assintomáticos, constituídos primariamente por células Schwann e fibroblastos, sendo os neurofibromas cutâneos os mais comuns (4). Os sítios mais comumente envolvidos na cabeça e no pescoço são a região frontal, as pálpebras, a parte posterior da região cervical, a língua, podendo causar obstrução das vias aéreas, distúrbios da mastigação, da deglutição, da fala, da função da língua e distorções cosméticas (5).

São critérios diagnósticos para a NFl, segundo a Conferência Consenso da NIH de 1987, revisada em 1997: manchas café-com-leite, neurofibromas, efélides axilares ou inguinais, glioma óptico, hamartomas de íris, lesões ósseas e história familiar positiva (4). Além desses achados, os pacientes com NFl apresentam risco aumentado de neoplasias do sistema nervoso central (neurofibromas plexiformes, gliomas ópticos, ependimomas, meningiomas, astrocitomas e feocromocitomas) e de tumores endócrinos (feocromocitomas, neoplasias da paratireóide, tumores carcinóides e CMT) (3).

Os nódulos da tireóide apresentam alta incidência na população geral. Dados norte-americanos estimam que $4 \%$ a $7 \%$ da população adulta apresentam nódulos palpáveis, sendo o maior desafio diagnóstico a exclusão de lesão tumoral maligna. Os que cursam com sintomas obstrutivos do trato aerodigestivo e os associados ao alto risco de neoplasia maligna necessitam de pronta avaliação diagnóstica. Inicialmente se realiza PAAF em virtude de seu baixo risco e custo-efetividade, ficando a ressecção cirúrgica reservada para os casos inconclusivos ou com sintomas compressivos importantes (6).

Reportamos o caso de uma paciente jovem, com quadro típico de NFl, sem alteração da função tireoidiana, que apresentava nódulo tireoidiano sem etiologia definida. Embora a NFl correlacione-se classicamente com CMT, outras neoplasias tireoidianas têm sido relatadas, como o carcinoma folicular e o papilar, tornando imperativo excluir a possibilidade de malignidade no presente caso (6-7).

Como as dosagens da calcitonina e do ACE estavam normais e a PAAF foi inconclusiva, foi realizada a tireoidectomia subtotal que evidenciou neurofibroma medin- do $3,7 \mathrm{~cm}$, em parênquima tireoidiano com bócio colóide nodular associado. Tendo em vista a raridade da apresentação, os poucos relatos na literatura e a falta de evidências, não existe um consenso para a melhor conduta, sendo realizado na maioria dos casos, pelos fatos expostos acima, o manejo cirúrgico com ressecção total ou parcial, dependendo da extensão da lesão.

\section{CONCLUSÃO}

A importância do caso deve-se não só à raridade e à benignidade desse tipo apresentação da NFl, mas da possibilidade de associação com neoplasia endócrina múltipla, fazendo parte do espectro o CMT. Este deve ser sempre excluído, já que se trata de um tumor agressivo que tem como tratamento preferencial a ressecção cirúrgica (8).

\section{REFERÊNCIAS}

1. Constant A, Acquaviva F. Neurinoma in the thyroid area. Presse Med. 1994 May 28;23(20):952.

2. Ciardi A, Pecorella I, Trombetta G, Memeo L, De Quarto A, Di Tondo U. An Unusual Case of Neurofibroma of the Thyroid Capsule. Pathol Oncol Res. 1997;3(4):293-5.

3. Hoff AO, Cote GJ, Gagel RF. Multiple endocrine neoplasias. Annu Rev Physiol. 2000;62:377-411.

4. Ferner RE. Neurofibromatosis 1 and neurofibromatosis 2: a twenty first century perspective. Lancet Neurol. 2007 Apr;6(4):340-51.

5. Greinwald J, Derkay CS, Schechter GL. Management of massive head and neck neurofibromas in children. Am J Otolaryngol. 1996 Mar-Apr;17(2):136-42.

6. Hegedüs L. Clinical practice. The thyroid nodule. N Engl J Med. 2004 Oct 21;351(17):1764-71.

7. Anagnostouli M, Piperingos G, Yapijakis C, Gourtzelidis P, Balafouta S, Zornas C, et all. Thyroid Gland neurofibroma in a NF1 patient. Acta Neurol Scand. 2002 Jul;106(1):58-61.

8. Wells SA, Franz C. Medullary carcinoma of the thyroid gland. World J Surg. 2000 Aug;24(8):952-6.

\section{Endereço para correspondência:}

Mateus Dornelles Severo

Cidade Universitária Professor José Mariano da Rocha Filho, Prédio 22, Rodovia RS 509,

97105-900 Santa Maria, RS

E-mail: mateusdsevero@pop.com.br 